\title{
The Hybridization of Distance Learning in Brazil - An Approach Imposed by Culture
}

Fredric Litto

The University of Sao Paulo

\begin{abstract}
Institutions of higher education in Brazil are seriously behind in their development of approaches which make use of distance education techniques, in part due to widespread lack of credibility of these approaches both inside and outside academic communities, but even more so because of the highly centralized control over all aspects of higher education on the part of the country's Ministry of Education. Despite the country's capacity and need to do so, the rigid and pedagogically conservative attitude of this Ministry over the last three decades, combined with the equally intransigent and politically-motivated decisions of the National Congress, have discouraged practically all attempts by educational institutions, public and private, to invest significantly in the development of innovative and far-reaching initiatives employing distance learning methods. Hybridization, or the combination, in the same course, of face-to-face situations for learning with those carried out using distance learning techniques, represents in Brazil is not an option motivated by pedagogical choice, but rather the only avenue legally permitted in the field of formal, degree-granting higher education.

Key Terms: distance learning, face-to-face learning, online learning, university course planning, regulation of distance education, resistance to change in education, education in Brazil, Brazil-educational policy.
\end{abstract}

\section{Introduction}

When James Taylor of the University of Southern Queensland, Australia, announced in his keynote address, "Fifth Generation Distance Education", at the 20th ICDE World Conference in Düsseldorf in April of 2001, that his University had for several years been maintaining fully-automated online degree-granting programs, it was clear to all present that distance learning had reached a new plateau. Everyone had suspected in years past that totally automated selflearning on a global scale would one day show its face; but most interested parties assumed it was still decades off. The very idea of total automation, with intervention by an instructor only when the student so requests, extends the envelope of possible action in distance learning, augmenting outreach by lowering 
The Hybridization of Distance Learning in Brazil - An Approach Imposed by Culture

costs per student, and including all those who are wanting to attempt higher education, as long as they are able to adapt to the pedagogical model offered. ${ }^{1}$

In Brazil, one of the world's most populous and economically important countries, cultural factors operating in the last three decades have held back the development of distance learning in higher education. And as incredible as it may seem, the advent of totally automated distance learning, as proposed by Australia, may actually help bring about the modernization needed by revealing the serious gap separating education in Brazil from the rest of the world. It is possible to foresee, in the not-too-distant future, a building-up of pressure within the academic community and society in general to release the arrested energy of those anxious to extend or to receive the benefits from distance learning. But when this happens, we may be forced to suffer many "worst practices" along with the "best."

\section{Societal and Institutional Contexts2}

The Federal Republic of Brazil is the fifth largest country in the world, exceeded in size only by Russia, Canada, China and the United States. It covers an area of 3,300,171 square miles (8,547,404 square kilometres), occupies about half of South America, and shares its border with all other countries on the continent except Chile and Ecuador. It is also the most populous country in the region and the fifth most populous in the world, with about 172 million inhabitants. The majority of Brazilians live in the south-central area, which includes the states of São Paulo (36.6 million), Minas Gerais (17.9 million), and Rio de Janeiro (14.3 million).

Brazil has the tenth largest economy in the world, with Gross National Product (GNP) of US $\$ 555$ billion in 1999, outweighing that of all other South American countries. Although highly diversified, the country is characterized by wide variations in levels of development. Brazil's economy reveals the simultaneous existence of the three "waves": Subsistence farming, labor-intensive industry, and aspects of a sophisticated information-society (e.g., in 2001, 90 percent of the national income tax declarations were delivered by citizens to government through the Internet).

Life expectancy in Brazil is only 70 years as compared with 86 years in the United States. Income distribution is, likewise, one of the worst in the world, according to data of UNESCO and OCDE: Ten percent richest possess practically half of the national wealth (37.9 percent), while ten percent poorest possess only 0.8 percent of the nation's wealth. UNESCO data show that there are 35 million illiterates over 15 years of age. Ninety-four percent of the population is served by electricity at home, 90 percent have radio, 87 percent have television and 32 percent have telephone service.

International Review of Research in Open and Distance Learning 
The Hybridization of Distance Learning in Brazil - An Approach Imposed by Culture

In 2000, there were in Brazil - from nursery schools to secondary education $48,924,730$ students (89.1 percent in public institutions), and 2,464,515 students enrolled in tertiary-level studies (36 percent in public institutions). The numbers of those successfully concluding formal education leaves much to be desired: in the period 1994-1999, only 58 percent of those of 14 years of age completed their primary school education; only 38 percent of those of 17 years of age completed their secondary school education. The percentage of the population 21 years of age who completed university-level studies was only 9 percent. On the other hand, women have a far better record than men in completing their studies: in 1998 they represented 56 percent of those enrolled in secondary schools and 54 percent of those in higher education; in that same year they comprised 53.6 percent of those completing primary education, 58.5 percent of those completing secondary education, and 61.4 percent of those completing tertiary education.

One of the major problems in primary and secondary education is the high level of repetition of the academic year by poorly prepared and poorly motivated students, exceeding 20 percent each year. This condition resulted, in the period 1996-1999, in the statistic that 23.2 percent of primary school enrollees were aged 15 years or older, and 38.7 percent of secondary school student enrollees aged 18 years or more.

According to the Ministry of Education, in 1999 only 7,695 primary and secondary schools (3.5 percent of the total) had access to the global computer network, and 67.2 percent of these were private schools. This should not be surprising considering that 64,000 schools (29.6 percent of the total) do not have electricity, less than 25 percent have school libraries, and only 11 percent have equipment for learning activities (e.g., science labs and the like).

The universe of institutions of higher education in Brazil totals 1,097, public and private, with approximately 2.5 million students and 173,000 professors. In 1999, half of the teaching faculty in the country possessed the Master's degree and 20 percent the Doctoral degree. There were 56,900 students studying for their Master's and 29,900 studying for their Doctorate. In 1999, 4,800 Doctorates were awarded in the country with 40 percent of the doctoral programs of study located in the three state universities of São Paulo, illustrating the concentration of research institutions, major libraries and other centers of knowledge in the southern area of the country.

Highly significant for the purposes of this study, is the fact that in the period 1994 to 1999, the increase in demand for secondary school education grew 57 percent, and that for higher education grew 57.6 percent, indicating that the general population had become aware of the necessity of obtaining the greatest amount of schooling possible in order to survive in the new world of economic competition. As examples, in 2000, 140,000 candidates sat for the entrance exams (for 8,000 openings) for the tuition-free state-run University of São Paulo; 56,000 sat for the 6,000 openings of the Federal University of Rio de Janeiro; and 32,000 sat for the 2,000 openings at the state-run University of the West of 
The Hybridization of Distance Learning in Brazil - An Approach Imposed by Culture

Paraná (effectively blocking admittance to 93 percent of the candidates). With the public sector unable to provide classrooms, instructors, or funds to accommodate greater numbers of students, the repercussions for increased demand for higher education have not been lost on the private sector, which is investing heavily to meet the demand. The option of using distance education to remedy this problem has been discussed in some quarters, but concrete measures have yet to be taken. As an example of the repressed demand in society for higher education, early in 2001 the State Government of Amazonas created a tuitionfree public institution for higher learning, announced cost-free entrance exams for 1,600 placements, and found itself submerged by 190,000 registrants, or 10 percent of the entire population of the State.

Perhaps the overriding influence determining the steadily increasing gap between Brazilian education and world-class examples elsewhere, is the contribution of Portuguese colonialist culture still permeating many sectors of Brazilian life. Although the Portuguese "discovered" Brazil in 1500 and immediately began colonizing activities, it was not until 1808 that the crown permitted domestic publication of Brazilian books, newspapers and periodicals. Likewise, from 1808 to 1934 , the only institutions of higher learning were isolated faculties of medicine, law and mining in a mere three or four cities. True multi-faculty universities only began in 1934. With the exception of one or two institutions connected with the public health studies, there was little scientific achievement until the 1970s. Public instruction began, modestly, only in the early part of the twentieth century. The free distribution of books to public school students started only in the 1960s. The Portuguese also left behind a highly bureaucratic, highly centralized organization of society, the heritage of an aristocratic tradition, which maintained and still maintains power in the hands of the very rich, and tolerates only certain kinds of democratic structures and processes which do not threaten their basic social architecture.

With the Constitution of 1988, the Ministry of Education became the supreme authority for higher education, responsible for maintaining quality through processes of prior approval and posterior punishment. Its highly centralizing power over both public and private institutions has created an environment in which educators and institutions hesitate to innovate or invest in new learning initiatives for fear of being struck down by unimaginative technicians of the Ministry or by their conservative external advisors. More seriously, the top/down model of control over education makes for a passive teaching community, initiating changes only in response to orders from above. In the same Constitution, states of Brazil are charged with supervision of secondary education, and municipalities with primary and nursery school education. But, in fact, the Ministry, contradictory to the Constitution, through regulations and recommendations having the equivalence of the force of law, and financial incentives, intervenes and dominates all levels of education.

This, of course, has become problematic for the country as a whole. As quali-

International Review of Research in Open and Distance Learning 
The Hybridization of Distance Learning in Brazil - An Approach Imposed by Culture

tative and quantitative outputs in education have been unsatisfactory in recent decades, it has also become clear that the highly concentrated centralizing power of the Ministry of Education, is no longer capable of dealing promptly with the increasing growth and complexity in the form of more students, more subjects, more professions, and more materials. But the question is even more crucial in the case of distance education at the tertiary level, which in Brazil has suffered arrested growth due to the myopic vision of the future, and a nostalgic view of past educational practices, particularly on the part of those in power.

Brazil is not a newcomer to distance education having witnessed the rise of correspondence courses in the early 1900's (many such courses are still popular with certain segments of the population), educational radio starting in 1923, and instructional television in the $1960 \mathrm{~s} .{ }^{3}$ Studies on distance education around the world in the 1970s placed Brazil among leaders like India, Spain and the United Kingdom; but governmental discontinuity destroyed this head start. Although Portugal itself has pushed forward with a new mentality, even having its own Open University, Brazil continues its colonial heritage of suspicion of change, and only reluctant shifts to new educational paradigms.

The Portuguese traditions of tutorship or trusteeship and the necessity of credentials have made Brazilian education, and society in general, a curious hodgepodge of regulations and customs. For example, to be employed by a newspaper, one must hold an undergraduate degree in journalism; to be a librarian, a Doctorate in library science is not sufficient - one must have the appropriate Bachelor's degree; and academic degrees from abroad in all fields must be approved before they can have validity in the country, and those degrees completed through distance education institutions, whether they are Brazilian or foreign, are automatically disregarded.

Although the Constitution of 1988 (Article 209) clearly states that universities have autonomy over curricula and administration, the Ministry ignores that fact and authorizes the opening of new graduate and undergraduate courses, which, in essence, homogenizes all efforts - thereby creating a one size must fit all. ${ }^{4}$ And even though the celebrated Article 80 "Lei de Diretrizes e Bases" (1996), an important document regulating all education in the country, declares that all university courses completed through distance learning and face-to-face approaches to be of equal validity, in reality the Ministry ignores this dictum and effectively does all it can to strangle nearly all attempts to establish distance learning. In the two years that it has officially received requests for approval of new distance education initiatives, the Ministry has approved only seven institutional projects, leaving 4,000 requests waiting in the wings for approval. Early in 2001, the Ministry announced it would receive no more requests, thereby giving privilege to those already in line, and unjustly disqualifying those institutions that wish to start distance learning activities.

It should be made clear, at this point, that the restrictions against distance learning on the part of the Ministry hold only for "formal" programs of graduate

International Review of Research in Open and Distance Learning 
The Hybridization of Distance Learning in Brazil - An Approach Imposed by Culture

and undergraduate studies leading to diplomas, which grant the right to practice a profession. Extension courses and other non-degree programs do not fall into the highly restricted category. Likewise, state authorities must approve all distance education courses designed for primary and secondary school students of any age, although these, too, are often quite conservative.

Certainly the most disheartening fact is that in the last three decades, 30 different attempts to create an "Open University" in Brazil have met with failure, primarily brought down by a combination of conservative thinking in the Ministry and lobbying influences in the National Congress (where many Federal Deputies and Senators are also the owners of private universities throughout the country, and not at all pleased with competition in their spheres of geographic monopoly). ${ }^{5}$ In 1996, the Ministry issued a ruling (Portaria No. 228 of 15 March) prohibiting the validation in Brazil of any post-graduate degrees awarded by foreign institutions for studies partially or totally conducted through distance learning, even when degrees are awarded in association with accredited Brazilian institutions. In late 2000, the Ministry announced that it would prosecute national or foreign institutions, which took out advertisements in local newspapers offering enrollments in distance education courses leading to academic degrees.

To anyone willing to stop and analyze the situation, it becomes clear that the very Ministry of Education, authorized by law to coordinate activities of higher education in the country, is, consciously or not, creating a situation for civil disobedience, for if potential students interested in pursuing university degrees characterized by "any time, any place learning," and are both willing and capable of so doing, then it behooves them to do so. And when we consider that few occupations in society require diplomas authenticated by the Ministry (the entire world of commerce and industry, for example, seeks competent workers, with or without credentials), then both future workers and their employers can simply ignore the Ministry and carry out advanced studies either in or outside the country, using distance learning techniques.

There seems to be little hope for improvement of the situation before 2003, when a new government will take office, hopefully with forward-looking education professionals. Until that time, Brazilian distance educators must content themselves with the smallest bits of evidence that the bureaucrats in Brasília do have an ear to the ground and are not totally unresponsive to society's call for redress. Two recent articles in the public press strongly criticizing the Ministry for its mishandling of the question of distance education seem to have had an effect, for on October 18, 2001, the Ministry issued a new ruling (Portaria No. 2,253 ), which now permits the use of "non-presence" methods (a euphemism for distance education) as a part of courses already accredited for conventional purposes, but "not to exceed 20 percent of the time expected for the completion of the entire course program." 6 The ruling further says that students may opt to participate or not in the distance part of learning, and that, in any case, all

International Review of Research in Open and Distance Learning 
The Hybridization of Distance Learning in Brazil - An Approach Imposed by Culture

final exams must be face-to-face. Finally, it requires that all modifications or new proposals must have prior authorization of their plan of instruction by the Ministry, or suffer intervention.

So the issues involved in this curious situation are:

1. Brazil badly needs distance education at the university level (a) to qualify the 44 percent of primary school teachers who have only high school diplomas or equivalents and who by law must have university degrees by 2007 ; (b) to meet the exploding demand for high school diplomas and university degrees; (c) to broaden the offerings of local universities through the presence in the country of distance education courses offered by foreign universities; and (d) to permit local universities to serve ever larger and more widespread segments of society.

2. The governmental authorities fail to recognize the potential benefits of distance education at the university level, or in the capacity of local educators to successfully execute programs involving distance learning. While waiting for significant changes, the hybridization of education, or the mixture of distance and face-to-face techniques, appears to be the only path possible for those institutions wishing to gain experience, consolidate the work of professional teams, and create a growing clientele for courses at a distance. Instead of its being an option in the arsenal of pedagogical arms, it is the sole path open at this time. Instead of allowing the option of placing the greater emphasis on the distance part of any course, and thereby facilitating the life of students who must work and who have families to care for, the rules require just the opposite.

The efficacy of face-to-face learning, which the Ministry of Education seems to hold paramount in spite of the poor overall results in all Brazilian education, presents new problems, as was observed by an American professor of law who complained that with his classroom full of students working on their laptops while he lectured, he had the distinct impression that though "present," the students were most likely "surfing" on the Web, involved in videogames, or mentally "checked out." " Likewise, in a recent study of benchmarks for online higher education, no mention was made among the 24 items, of hybridization and its place in distance learning. ${ }^{8}$ And finally, it must be noted that Brazil has no tradition of the residential liberal arts college and its humanistic tradition. The author knows of only one institution in the country, in a rural area, that has residential facilities, and none that has a curriculum in any way similar to the North-American liberal arts model. Hence, the arguments against courses featuring hybridization, at least those that emphasize distance learning, such as are found in the Kenyon College manifesto, "Proximity Learning," cannot be understood in the Brazilian educational context. ${ }^{9}$

In order to determine how institutions accommodate themselves to this reality,

International Review of Research in Open and Distance Learning 
The Hybridization of Distance Learning in Brazil - An Approach Imposed by Culture

an informal questionnaire was sent to 67 institutions of higher learning that were on record, as having some distance learning activities. Since it was anticipated that comparisons would be difficult given the wide variety of cases, the questionnaire sought essentially qualitative information. Only ten questionnaires were returned within the allotted timeframe and their responses will be coalesced into the following section. In accordance with a promise of confidentiality so as to elicit honest responses, the identities of the institutions will not be revealed. All of the responses came from institutions in the South-Center and South of the country operating at the graduate and undergraduate levels: four were large research universities funded by the Federal Government; two were large Catholic Universities with a research tradition; one was a Federal institution for technological education; one was a private but not-for-profit institution for technological education; one was a large state university with a strong research tradition; and the last was a small private university without a research tradition, located in the interior of the country. One began its distance learning activities in 1995; two began in 1996; one began in 1997; four began in 1999; and one began in 2000. One stated that its courses were only offered for its own teaching staff; one said that the majority of students in its courses participated from a great distance; while the rest noted that their students in distance learning were a mixture of local and distance enrollees.

\section{Subsystems of the Distance Learning Universe}

\section{Course Subsystem}

Almost all respondents admitted that a principal motive for initiating distance learning courses was the desire to innovate, either on the part of the administration or on the part of the teaching staff. Most admitted to having encountered preconceived, negative ideas about distance learning among their colleagues or administrators, which hampered their work. Several reported that their work was motivated more by idealism than by any other motive. Some were motivated by the desire to reach out to working professionals who had no opportunity to participate in frequent conventional face-to-face sessions, but could do so infrequently, staying with the course through distance techniques. Only one emphasized belief in the necessity of requiring face-to-face meetings so as to better "socialize, motivate and stimulate" the students. Almost half admitted to choosing hybridization due to the Ministry's stance on the question. Half considered that there was as yet "not the proper culture" in Brazil for "total" distance education. One university, whose work had originally been financed by the Ministry had to stop its activities due to "discontinuity" of their financing. Most noted that a major difficulty was the preparation of production teams to develop the learning materials, frequently done by professionals "improvised" for the occasion. On the positive side, almost all agreed that their major achieve-

International Review of Research in Open and Distance Learning 
The Hybridization of Distance Learning in Brazil - An Approach Imposed by Culture

ment was the "didactic" success of the courses, and the consequent change of opinion in the environment about the efficacy of distance learning, especially with a high-rate of satisfaction on the part of students. One institution used only self-evaluation of their students, and was satisfied with the results. Several revealed enormous satisfaction in having successfully "democratized" access to higher learning for non-conventional students, and all were satisfied that the experience gained made all the efforts worthwhile.

\section{Students Subsystem}

Some complained that student participants were not yet ready for distance learning, abandoning courses when it became clear that they required as much or more effort than conventional courses. One admitted that having as students adults who had been away from formal learning for many years created a number of problems of motivation. Another observed that even with a low tuition rate, payment was a hardship for many students. Three reported no problem whatever with regard to students. On the positive side, one reported satisfaction in having maintained a drop-out rate of less than 5 percent with 300 students over a three year period. Another was overjoyed at having been able to recruit and retain students from the furthest reaches of the country (particularly the distant Amazon region). Overall, the greatest satisfaction was in building the confidence of students in the workings of distance education, even though all courses included elements of face-to-face learning.

\section{Regulatory Subsystem}

Only two respondents declared having no problems with regulatory issues. All the rest, admitted to having enormous problems in obtaining approval from internal committees of their institutions, one saying that his institution "was incapable of understanding the new paradigm of distance learning." Incomprehension, long delays in gaining approval from institutional authorities were common sources of complaint. Two respondents complained of the lack of orientation on the part of the Ministry of Education as a major source of frustration. For six of the institutions, it was still too early to offer opinion on the achievements in this area, but four admitted that despite regulatory restrictions, they had plans to expand the number and level of their courses.

\section{Logistical Subsystem}

Half of the respondents observed that their principal problem in this area was the training of production staff, since most had no prior experience with distance learning. Preparing instructors to be content providers was another on-going 
The Hybridization of Distance Learning in Brazil - An Approach Imposed by Culture

problem for some. One respondent said that his institution had still not accepted the idea that multi-talented staff is needed to produce quality distance learning courses. Various commentaries were offered citing the precariousness of the classrooms used, and the fact that institutions still think only of the face-toface paradigm and are thus unprepared for new approaches. On the positive side, six responded that their greatest achievement was managing to train their staff adequately enough to get the job done, and one was pleased that he had recruited ex-students of the distance education course to serve as volunteer monitors in new courses. Another said that the greatest achievement in this area was managing to integrate software and hardware for distance learning with the general structure of informatics of his institution.

\section{Technological Subsystem}

Complaints with respect to the technological subsystem focused on costs of acquiring and maintaining the technologies for connectivity and the precariousness of telecommunications services in the country. Temperamental servers and unsatisfactory results with software acquired to manage online education were also noted. Five noted they had successfully developed their own software interfaces for distance learning; two were delighted that after a long waiting period their hardware had arrived, making it possible to upgrade their technological platform.

\section{Unintended Consequences}

The author earnestly believes that it is likely that one of the unintended consequences of the Ministry of Education's severity with regard to the development of distance learning in higher education is that it will eventually create such a backup, a log-jam, if you will, of requests to initiate new programs (there are already 4,000 requests pending), that responding to public outcry, a higher governmental authority will bring about a blanket amnesty, approving without any criteria whatsoever, all requests, good and bad. ${ }^{10}$

When asked about unintended consequences experienced in their pioneering work, respondents to the questionnaire stressed unexpected disappointments suffered while attempting to construct their projects. Most revealed profound dismay at the degree of non-support from departmental colleagues; one admitted deception at the fact that Ministerial funds had been promised to permit project continuity, but were never forthcoming. Two others complained of "exaggerated governmental bureacracy, which impedes amplifying successful experience," and another was disheartened by the lack of support from industry, which stands to benefit from better-qualified workers trained through distance education.

International Review of Research in Open and Distance Learning 
The Hybridization of Distance Learning in Brazil - An Approach Imposed by Culture

\section{Implications}

When asked what final advice they could give to newcomers beginning work in distance education, respondents answered: "Be persistent, demonstrate reliability, credibility and quality," "concern yourself first with financial matters, then with training your staff;" "always take full advantage of the face-to-face parts of courses - they are more important than the distance part, but not always possible to use well;" "always use the face-to-face part to build integration and motivation among the students and maximize the use of audio-visual material because it augments the sense of personal contact among students." These statements reveal an optimistic desire to forge ahead with efforts in distance learning opportunities, despite the legal restraints currently in place. The respondents, as a group, demonstrated a particularly Brazilian quality of going forward against adverse conditions, of improvisation and native ingenuity to reach one's goal, be they personal or institutional. The lesson to be learned here is that it should be the role of the state to lead society to new levels of productivity and collective well being, rather than to hold valid initiatives. Although distance education around the world is making great strides in employing both newer and older technologies to expand greater access to learning to ever-larger segments of society, in some quarters, either due to deep-seated skepticism within the culture, or due to hidden agendas on the part of those in power, those social advances are still ignored.

\section{Conclusions}

We have seen that highly centralized power and decision making in the educational sector runs counter to society's need for flexibility and agility. The augmenting of complexity in human affairs, and respect for the tenet that "one size does not fit all," makes it impossible for society to accept, on the part of the state, immobility and reactionary behavior. With its discontinuous experience with distance learning, Brazil is woefully behind other nations in using new pedagogically sound solutions to benefit its large population. While Brazil's population has demonstrated learning needs and structural constraints that all point to the necessary and massive use of distance education, its Ministry of Education resists permitting the healthy and normal expansion of distance learning in the area of higher education, and more conservative members of the academic community hamper as best they can local, regional and national attempts to extend distance education to all sectors of higher learning. The employment of hybridization in distance learning activities constitutes not only the only path that can legally be chosen today and in the foreseeable future, but also a "comfort zone" approach in a somewhat hostile environment. It remains to be seen, however, how long it will take for pressure to build up calling for change, relaxation of the restraints, and the consequences, which may not be able to

International Review of Research in Open and Distance Learning 
The Hybridization of Distance Learning in Brazil - An Approach Imposed by Culture

exclude exactly those "bad practices" which the Ministry and other educational conservatives are presently claiming they are trying to avoid.

International Review of Research in Open and Distance Learning 
The Hybridization of Distance Learning in Brazil - An Approach Imposed by Culture

\section{Endnotes}

1. [Retrieved August 3, 2001: http: //wwwfernuni-hagen.de /ICDE/ D- 2001/ final/keynote_speeches/ Wednesday/taylor_keynote .pdf. ]

2. The factual data is this section is a composite of information retrieved from the following sources, all retrieved July 15, 2001: http://wwwbritannica.com. ; http: //www.ibge.gov.br /ibge/populacao. ; http:// www.socinfo.org.br /livro _verde/ capitulo_4. htm. ; http:// www.mec.gov.br /home/legislacao/default. shtm. ; http:// www.inep.gov.br/censo/censo2000/sinopse2000. htm. ; http:// www.inep.gov.br /noticias/news_344. htm. ; http:// www.fnde.gov.br/ instituicao/indicadores. htm. ; http:// www.unesco.org/iau/cd-data/ br.rtf. ; http:// www.capes. gov.br. ; ] The author admits to having some doubts about data furnished by governmental authorities, especially when it is very favorable, and feels more comfortable when it is not favorable. As M.K. Bacchus of the University of Alberta, Canada, noted some years ago in a book review concerning ministries of education in small states, "we must be careful in accepting reports of 'successful administrative practices" offered by civil servants currently employed." "Though close to the scene, they may be far from objective." "They sometimes conceal the major weaknesses of their administrative structures, or conveniently attribute these failings to the problem of size." Everything looks fine when discordant voices are excluded. See M.K. Bacchus (1992), Review of M. Bray, ed., Ministries of Education in Small States: Case Studies of Organization and Management, in Canadian and International Education (Calgary), Vol. 21, No. 1, 91-95.

3. Distance Education in the E-9 CountriesThe Development and Future of Distance Education Programmes in the Nine High-Population Countries. Paris: UNESCO, 2001; on Brazil, 18-21.

4. Alves,, João Roberto Moreira (1994). A Educação a Distância no Brasil: Sintese Histórica e Perspectivas. Rio de Janeiro: Instituto de Pesquisas Avançadas em Educação.

5. As Bases Legais da Educação a Distância no Brasil. Revista Estudos (ABMES, Brasília), Ano 17, No. 26 (novembro). [Retrieved July 10, 2001] http://www.abmes.org.br/abmes/publica/Revista/estud26/joao.htm.

6. Litto, Fredric M. (2001). "Educação Inflexível e Tutelada", Correio Brasilense (Brasília), August 15; p.2; "O MEC é um Obstáculo Formidável para a Educação à Distância no País", O Globo (Rio de Janeiro), October 8, 2001.

7. Ayres, Ian (2001) "Lectures vs. Laptops", The New York Times, March 20, Opinion Page. [Retrieved July 6, 2001] http://www.nytimes.com/2001/03/20/ opinion/20ayre.html.

8. Quality on the LineBenchmarks for Success in Internet-Based Distance Ed-

International Review of Research in Open and Distance Learning 
The Hybridization of Distance Learning in Brazil - An Approach Imposed by Culture

ucation. Washington, D.C.: Institute for Higher Education Policy, 2000. [Retrieved July 8, 2001] http://www.ihep.com/PUBs/PDF/Quality.pdf. .

9. "Proximity Learning", Kenyon College [Retrieved July 8, 2001] http://enhancedlearningorg

10. ( For a recent sampler of unintended consequences, see Gillon, Steven M2001). "Unintended Consequences - Why Our Plans Don't Go According to Plan", The Futurist, March-April, 49-55.

Citation Format

Litto, Fredric (January, 2002) The Hybridization of Distance Learning in Brazil - An Approach Imposed by Culture. International Review of Research in Open and Distance Learning: 2, 2. http://www.icaap.org/iuicode?149.2.2.6 